\title{
ILCEA
}

Revue de l'Institut des langues et cultures

d'Europe, Amérique, Afrique, Asie et Australie

$41 \mid 2020$

Escrituras nómadas en el mundo hispánico contemporáneo

\section{León de Greiff: viajero inmóvil y nómada intelectual}

León de Greiff: a Motionless Traveler and a Nomadic Intellectual

León de Grieff : voyageur immobile et intellectuel nomade

\section{Marco Ramírez Rojas}

\section{OpenEdition}

Journals

Edición electrónica

URL: http://journals.openedition.org/ilcea/11207

DOI: 10.4000/ilcea.11207

ISSN: 2101-0609

Editor

UGA Éditions/Université Grenoble Alpes

Edición impresa

ISBN: 978-2-37747-224-6

ISSN: $1639-6073$

\section{Referencia electrónica}

Marco Ramírez Rojas, «León de Greiff: viajero inmóvil y nómada intelectual», ILCEA [En línea], 41 |

2020, Publicado el 09 octubre 2020, consultado el 05 febrero 2021. URL: http://

journals.openedition.org/ilcea/11207 ; DOI: https://doi.org/10.4000/ilcea.11207

Este documento fue generado automáticamente el 5 febrero 2021.

(c) ILCEA 


\title{
León de Greiff: viajero inmóvil y nómada intelectual
}

\author{
León de Greiff: a Motionless Traveler and a Nomadic Intellectual \\ León de Grieff : voyageur immobile et intellectuel nomade
}

Marco Ramírez Rojas

Et même si le voyage est immobile, même s'il se
fait sur place, imperceptible, inattendu,
souterrain, nous devons demander quels sont nos
nomades aujourd'hui, qui sont vraiment nos
nietzschéens?
Gilles Deleuze, La pensée nomade (2002: 362$)$

\section{Introducción: León de Greiff, viajero in situ}

1 El presente artículo se propone observar la obra del poeta colombiano León de Greiff (1895-1976) como una manifestación de pensamiento nómada y como un ejercicio poético de desterritorialización y de trazado de cartografías intelectuales alternativas. En el marco de este estudio, se busca interpretar los textos greiffianos como una práctica literaria cosmopolita que opera por medio de una rearticulación subjetiva del archivo cultural y que propone una desestabilización de las líneas de organización cronológicas y geográficas tradicionales. Mediante una práctica de cosmopolitismo localizado y por medio de su caprichosa reorganización de conocimientos culturales y genealogías intelectuales, León de Greiff propone una renegociación simbólica de sus lazos de afiliación y pretensiones universalistas. Este último gesto, finalmente, se plantea como una estratégica toma de posición que cuestiona la situación de marginalidad del espacio latinoamericano respecto a los centros culturales consagrados.

2 A pesar de que León de Greiff no goza del mismo renombre internacional que otros autores contemporáneos suyos, su obra ocupa un lugar central dentro de la historia de la poesía colombiana moderna ${ }^{1}$. Sus publicaciones, que abarcan un período de cinco 
décadas ${ }^{2}$, han sido observadas por la crítica como una oscilación entre la última ola del modernismo y unos destellos vanguardistas que no llegan a constituirse con la misma radical experimentalidad que en la obra de otros contemporáneos como Vicente Huidobro, César Vallejo, Oliverio Girondo o José Juan Tablada. A lo largo de sus ocho «mamotretos» - como de Greiff designa irónicamente a sus volúmenes- se hacen reconocibles los elementos que caracterizan su escritura: el uso de un lenguaje polimorfo y proteico que entremezcla vocablos medievales, neologismos, al igual que palabras de diversas artes y disciplinas; la presencia de heterónimos y personajes que reaparecen episódicamente a lo largo de su obra; el acopio de abundantes referentes culturales que usa de manera caprichosa e irónica. Este último es, justamente, uno de los aspectos más cruciales para el estudio de su cosmopolitismo y su nomadismo intelectual. El amplio espectro de conocimientos y tradiciones literarias y culturales de los que hace acopio la obra greiffiana podría comprenderse, así, a la manera de lo que Ericka Beckman plantea como "estéticas de catálogo» (2013: 43), rasgo que comparte con otros modernistas como Gutiérrez Nájera, Rubén Darío y Julián del Casal ${ }^{3}$.

Debe tenerse en cuenta, asimismo, que el cosmopolitismo greiffiano es de signo bastante particular. Al igual que sucede con otros poetas latinoamericanos cuyas obras se articulan en torno a un impulso de apertura cultural y de apropiación de conocimientos de diversas latitudes y geografías -como son los casos paradigmáticos de Julián del Casal y Lezama Lima-, el suyo es un cosmopolitismo inmóvil. León de Greiff es un viajero estático, un trotamundos de sillón. En su «Relato del catabucalesista» -incluido en su séptimo mamotreto, Velero paradójico, de 1957- se hace explícita esta poética del viaje inmóvil a través de la confesión de uno de sus alterego:

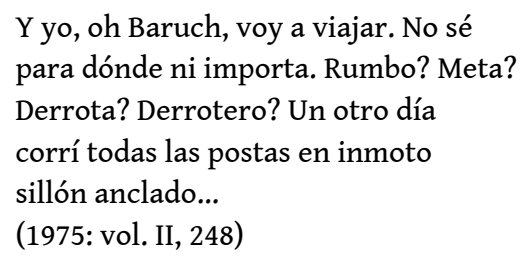

4 Es un dato conocido de su biografía que León de Greiff no viajó por fuera de los límites de su país durante los primeros cincuenta años de su vida ${ }^{4}$. Pero, a pesar de lo anterior, en su obra poética se reclama ya desde sus primeros textos como un ciudadano del mundo, un trashumante conocedor de todos los caminos ${ }^{5}$. Desde los espacios urbanos de Bogotá y Medellín, asentado en el «inmoto sillón anclado» de su biblioteca, construye un imaginario poético global que abarca varios continentes y distintas épocas y proyecta una cartografía por la que transita con la libertad de un nómada que viaja de un texto a otro sin cuidarse de las distancias, desplazándose sin problemas de una conversación con un poeta moderno a la conversación con un contemporáneo, acortando distancias de siglos.

5 Es por estos motivos que puede considerarse la obra greiffiana como una manifestación de un nomadismo in situ. Su literatura aparece, bajo esta perspectiva, como un fenómeno de errancia que se efectúa sin salir del espacio de sus habitaciones. La suya no es la literatura de un viajero ni la de un migrante puesto que no depende de desplazamientos físicos ni tampoco se impone la tarea de consignar impresiones de cosas vistas. Su apropiación y asimilación del mundo se realiza a partir de un espacio amurallado de libros. Esta es, justamente, la imagen que de Greiff elabora ya desde su 
poemario inicial y que marca el lugar desde el que van a elaborarse sus posteriores aventuras cosmopolitas:

VII

Todo está lleno de volúmenes,

Unos amables, otros crueles...

(...)

Mi camarín, mis anaqueles,

Todo está lleno de volúmenes,

Unos amables, otros crueles...

(1975: vol. I, 59)

Libracos, mamotretos, infolios y papeles,

Mi inercia, tardamente, rebuja y desordena,

Un cielo azul por la ventana. Lejos, suena,

La vida innumerable de la ciudad...

(1975: vol. I, 24)

En estos dos poemas de Tergiversaciones aparece configurado el espacio simbólico de la habitación en la que se concentran algunos elementos claves para la estética greiffiana y para su construcción de un imaginario universal: 1) la sobreabundancia de materiales escritos y conocimiento posible, 2) la condición de inmovilidad, y 3) el relegar la experiencia directa del mundo a un segundo plano.

En el centro de este maelstrom de libros que funge como archivo personal greiffiano, se cumplen todos los tránsitos de su poesía, a través de una cartografía poética que se extiende por Europa, los países escandinavos, Asia Central, Asia Menor, Medio Oriente, y el propio espacio americano. Todos sus viajes se verifican en las estanterías de su biblioteca y siguen los mapas trazados al azar de los contactos y contagios de los libros que se apilan uno junto a otro. Es bajo esta forma de acumulación de conocimientos escritos que se despliega su «deseo de mundo»-tomando el término conceptualizado por Mariano Siskind $(2014)^{6}-$, su impulso expansivo y su necesidad de trazar líneas de diálogo. De la misma forma, su ensanchamiento de horizontes culturales y la creación de inesperadas líneas de afiliación le permiten replantear su propia condición de marginalidad respecto a la tradición literaria global.

\section{Nomadismo y viajeros itinerantes}

8 Para proponer una lectura del nomadismo en la obra greiffiana deben considerarse dos aspectos fundamentales. El primero es la construcción de un imaginario poético que, desde un anclaje inmóvil, se articula siguiendo un recorrido intelectual itinerante. El segundo, es la construcción de personajes que se presentan como manifestaciones diversas del arquetipo del viajero. El punto inicial puede ser observado tomando como apoyo las ideas que Deleuze y Guatari presentan en Mil mesetas, donde proponen justamente un desarrollo teórico de lo que ellos comprenden como un nomadismo inmóvil'?:

...a propósito de estos nómadas se puede decir, como lo sugiere Toynbee: no se mueven. Son nómadas a fuerza de no moverse, de no migrar, de mantenerse en un espacio liso que se niegan a abandonar, y que sólo abandonan para conquistar y morir... los viajes no se distinguen ni por la cualidad objetiva de los lugares ni por la cantidad mesurable de movimiento -ni por algo que estaría únicamente en el espíritu- sino por el modo de espacialización, por la manera de estar en el espacio, de relacionarse con el espacio.

(2002: 490) 
Cuando Deleuze y Guatari observan que los verdaderos nómadas son aquellos que «no se mueven», debe comprenderse el valor relativo de esta afirmación. No se refieren estrictamente a los desplazamientos en la geografía sino a la manera como los individuos ocupan y recorren los espacios. Un nómada «no se mueve» en la medida en que no va de un territorio de coordenadas y ordenamientos precisos a otro cuya cartografía ha sido ya trazada de antemano y a la cual debe adaptarse. Esta no es la naturaleza de sus movimientos y, por ello, Deleuze y Guatari toman la precaución de anotar que «el nómada no debe confundirse con el migrante» (2002: 385). Por el contrario, el nomadismo opera por errancia y su deambular tiene como objetivo borrar trazados previos y circular por espacios que no han sido previamente codificados. Así, a pesar de que circule sin descanso, puede decirse que «no se mueve» porque habita de forma permanente un espacio que rechaza la estabilización de un trazado.

Como se ha expuesto anteriormente, las circunstancias biográficas de León de Greiff hacen de él, al menos durante cinco décadas, un errante inmóvil en el sentido más literal del término. La dimensión nomádica de su obra ha de señalarse al interior mismo de sus páginas. Sus lectores deben seguir las rutas a las que lo empuja su «deseo de mundo» en las fatigosas listas de referencias, y las profusas enumeraciones que nutren el cuerpo de sus poemas y el diseño de sus cartografías literarias. Una revisión transversal de su corpus poético, así sea breve, resulta necesaria para sustentar esta afirmación. Para evidenciar la amplitud de su arco de curiosidad y los distintos lugares de su frecuentación poética nótese, por ejemplo, la sucesión de estos temas y presencias poéticos que conviven en su obra: en el «Relato de Gaspar» se escenifica un diálogo amistoso con Arthur Rimbaud, situándose en la misma dimensión histórica que el poeta francés; en el fragmento "XVIII» de Prosas de Gaspar se reclama como compañero y coetáneo del poeta medieval François Villon; en el poema díptico «Breve canción de marcha» teatraliza un diálogo amoroso entre la figura mítica de un vikingo y la presencia de una mujer de Medio Oriente; y en su «Relato de Harald el Oscuro» se identifica con el personaje de la leyenda artúrica de Lancelot du Lac. Baste este breve recuento de visitaciones y apropiaciones literarias de tan diversos orígenes para justificar la concepción de la obra greiffiana como un producto de nomadismo libresco.

11 El segundo aspecto observable es el de las múltiples presencias viajeras e itinerantes que hacen parte del imaginario greiffiano. La obra del colombiano está poblada de voces y personajes que encarnan el paradigma del viajero errante. De Greiff idealiza y convierte a la figura del explorador en el centro de su mitología poética. Su arquetipo del aventurero se multiplica en distintas máscaras y encarnaciones que alternativamente aparecen bajo la forma de referencias literarias a Ulises, Simbad, Ahasvero, Ibn-Batuta, Jasón, vikingos, piratas y otros navegantes. Sus alter-ego también siguen este impulso de continuo movimiento y los vemos recorriendo tanto las geografías americanas como aquellas de Europa, Asia y Medio Oriente. Ya desde Tergiversaciones, hallamos poemas cantados por juglares errantes que se construyen bajo el signo de la itinerancia. En la «Balada ahasverica del ministril, trovero y juglar» se recurre a esta figura:

Ministril, trovero, juglar

De alma singular...

Vago de todos los caminos:

Tus innúmeros rastros

Confundan al viajero

Del futuro...! 


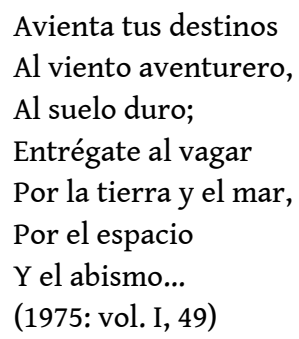
también que, a pesar de sus numerosas variaciones, todas las figuras del viajero conjuradas por de Greiff tienen un elemento de conexión: la indefinición de sus destinos y la multidireccionalidad de sus trayectos. A pesar de que las rutas de cada personaje son distintas unas de otras, todas ellas se guían por la misma brújula del azar. Teniendo esto en cuenta, puede considerarse, pues, que en la poesía del colombiano la idea del viaje no tiene como sustento la necesidad de desplazarse entre un puerto de salida y uno de llegada, sino el de habitar el espacio de tránsito. Tanto para los personajes greiffianos como para la figura del nómada, teorizada por Deleuze y Guatari, es el «entre-dos», el intervalo entre una y otra orilla, el que adquiere «toda la consistencia y goza de una autonomía y de una dirección propias» (2002: 385). Justamente esto es lo que se enfatiza en esta «Balada ahasverica» en la que se celebra el ser «vago» -tanto en su sentido de ser improductivo como en el de no tener destino final- de «todos los caminos».

La voluntad de perpetuar el viaje como tránsito constante se halla aunada en la poética greiffiana a la noción del «azar», de los encuentros fortuitos de nuevas rutas y caminos. En este concepto cifra también la idea de lo no-planeado, del desplazamiento hacia territorios que no están cartografiados. En el ya mencionado «Relato de Harald el Oscuro", incluido en Variaciones alredor de nada, se ejemplifica esta idea. El personaje que allí habla $-\mathrm{y}$ que entra en un juego de múltiples identificaciones en las que de forma alternativa se presenta como Harald, Tristán de Leonís y Lancelot- presenta su aventura como una navegación sin rumbo:

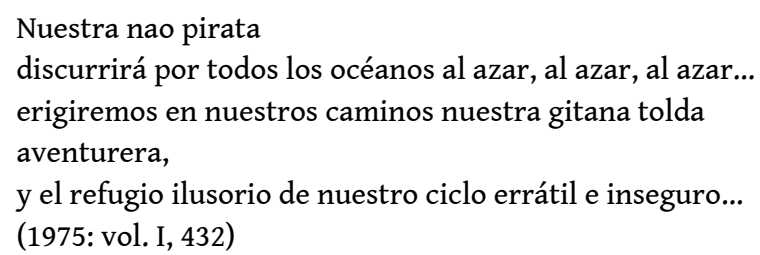

El poema configura un espacio donde las coordenadas de navegación se ven reemplazadas por un método de constante improvisación, trayectos fluctuantes y decisiones aleatorias. El mar ofrece, así, una apertura al trazado de vectores cambiantes que no se determinan por metas ni por puntos de llegada. Apelando a la terminología deleuziana, el «espacio liso» del mar por el que transita Harald el Oscuro también «está 
ocupado por acontecimientos» mucho más que «por cosas formadas o percibidas» (2002: 487). El dominio del azar se presenta allí como un horizonte de apariciones, abierto a distintas posibilidades de incidencia. Apariciones que, potencialmente, modificarían de forma constante el trayecto del viaje.

El anterior poema es ilustrativo del plano en el que se sitúan muchos otros de los personajes greiffianos que repiten un similar vagabundaje. El apartado «XXII» de las Prosas de Gaspar ilustra también la configuración de estos «espacios lisos» en la poesía del colombiano. En la narración de este otro heterónimo greiffiano se nos presenta la hoja de ruta imprecisa de sus aventuras marítimas:

Navega de conserva con el cansancio (pesado paquebote), mi fino yate ligero, mi velígero clipper - no con rumbo a Erewhon, Thule o Bizancio (pues la rima no es rumbo) y ni de tumbo en tumbo, sino en un lento navegar confiado, y sin mirar el astrolabio ni acudir a la brújula ni a seña alguna o signo.

Y así desde hace tardos años: mañana serán $n$ siglos y unas pocas semanas.

(1975: vol. I, 305)

La nave de este poema circula, entonces, en un espacio dentro del cual puede improvisar su ruta y rearticular sus trayectos conforme avanza. Aquí la dinámica de su recorrido es esencialmente la del nómada que no se encamina por trayectos fijos («no con rumbo a Erewhon, Thule o Bizancio») ni tampoco estructura su construcción textual siguiendo convenciones genéricas o discursivas estrictas («pues la rima no es rumbo»). El ejercicio que aquí se efectúa difuma las coordenadas de circulación y cuestiona la teleología del viaje. Así observado, el suyo podría incluso calificarse adaptando las ideas que Ana Cecilia Olmos plantea para interpretar la novelística latinoamericana de corte global contemporánea- como un "arte desterritorializado» que «desestabiliza los presupuestos identitarios nacionales» y pone en escena personajes «itinerantes» que «establecen vínculos más laxos con el territorio y colocan en cuestión la identificación lineal con la cultura de origen» $(2016: 37)^{11}$.

\section{Desdibujar y redibujar cartografías intelectuales}

Aunque la práctica greiffiana de desdibujamiento de mapas queda ya ilustrada en los textos comentados anteriormente, se hace necesario observar con mayor detenimiento este proceso de tergiversaciones cartográficas que pone en marcha. Uno de los textos en los que este proceso de rearticulación se enfrenta a una dimensión de carácter global es la «Farsa de los pingüinos peripatéticos». Este no solamente es uno de los poemas más humorísticos e irónicos de toda su obra sino también uno de los más significativos en términos de prácticas de desterritorialización y exploraciones de carácter cosmopolita. De Greiff cataloga este poema como una «rapsodia» y la atribuye a un trío de heterónimos coautores: Matías Aldecoa, Leo le Gris y Gaspar Von der Nacht. Esta composición que alterna diversos esquemas métricos y rítmicos se compone imitando sin demasiada fidelidad una composición musical que consta de un «Preludio», «Ronda Prima», «Ronda Segunda», «Giga», «Interludio» y «Ronda Final». En ella se hace un recuento de los desplazamientos de la tropa simbólico-humorística de «pingüinos peripatéticos»:

de abigarrada variedad innúmera

...

pingüinos asaz lindos y asaz feos

torpes y asaz geniales 


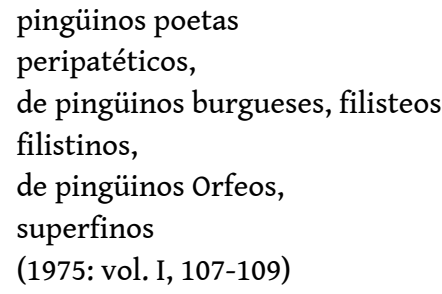

Estas figuras, que operan casi como una alegoría caricaturesca de la humanidad, atraviesan el globo moviéndose en caravana entre los extremos polares y las geografías del trópico. En su tono jocoso, el poema transparenta una voluntad bastante seria de recomponer la imagen del mapa mundial y abolir las líneas de división trazadas que responden a convenciones históricas y prácticas científicas. En las estrofas finales del «Preludio» esta intención se hace explícita:

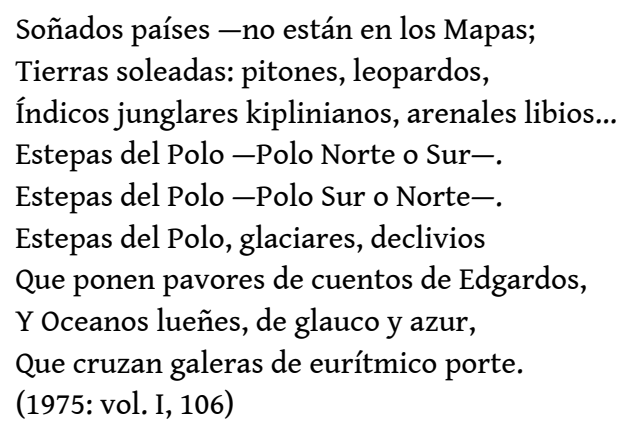

El recorrido de los personajes de este poema, que se desplazan por trayectos multidireccionales y sin una intencionalidad fija, pueden claramente calificarse como nomádico. Pero, adicionalmente, debe observarse también que sus rutas reconfiguran las coordenadas objetivas, las categorías geográficas y las líneas cronológicas del mapa global por el que circulan. Las líneas de recorrido de los personajes irónicos de estos pingüinos peripatéticos rediseñan su propio mapa mundi a partir de una visión que puede reconocerse como marcadamente «literaturizada». Es decir que, en lugar de ceñirse a las coordenadas preestablecidas de divisiones territoriales, de Greiff despliega un mapa que interpreta a partir de conexiones literarias, artísticas, intelectuales y filosóficas. Estos trayectos no se ajustan al mapa físico y político del territorio, sino que se superponen al mismo. Observemos en la cita anterior de qué forma las menciones a topografías específicas sólo ganan un peso significativo cuando se atan a las fuentes literarias que los significan. El espacio de la jungla del sudeste asiático solo se hace visible a través de la pantalla poética de Kipling y por esto se tornan en «junglares kiplinianos». Así mismo, la referencia a los paisajes desolados y fríos de los Polos se comprende únicamente en la medida de una relación analógica con la obra de Edgar Allan Poe. De esta forma el tejido de referencias librescas se convierte en la verdadera hoja de ruta.

21 En su ensayo sobre el descentramiento del «Yo» en la obra greiffiana, Oscar Salamanca observa que en «De Greiff hay una crítica a la noción indivisible del sujeto y su percepción estable de la realidad a través de la desarticulación de las partes constitutivas de la enunciación» (2015: 68). Retomando este postulado, es posible observar que también bajo esta óptica la noción de espacio y la construcción de territorios no se hallan sujetos a los requisitos de una cartografía geográfica estabilizada. Así como puede señalarse en de Greiff una desarticulación de la unidad y coherencia del «yo», también se hace visible un cambio radical en su construcción y 
percepción del espacio. En su obra se fragmenta la noción de continuidad objetiva del territorio y también se rearticulan las nociones de desplazamiento y distancia sobre un territorio que ya no es físico sino meramente libresco. En la obra greiffiana la literatura cumple una función desterritorializadora que superpone redes de conexión poéticas o filosóficas flexibles y que exige al lector una adaptación a esta lógica de desplazamientos inestables y fluctuantes. Este ejercicio de reajuste en el proceso de lectura se hace especialmente necesario en un fragmento como el de la «Ronda Final» de la «Farsa de los pingüinos peripatéticos» donde León de Greiff hace una enumeración de conexiones filosóficas que se plantean como un recorrido transversal tanto de la historia como de la geografía mundial. En la enumeración de las deambulaciones de los personajes de este texto se pasa revista a:

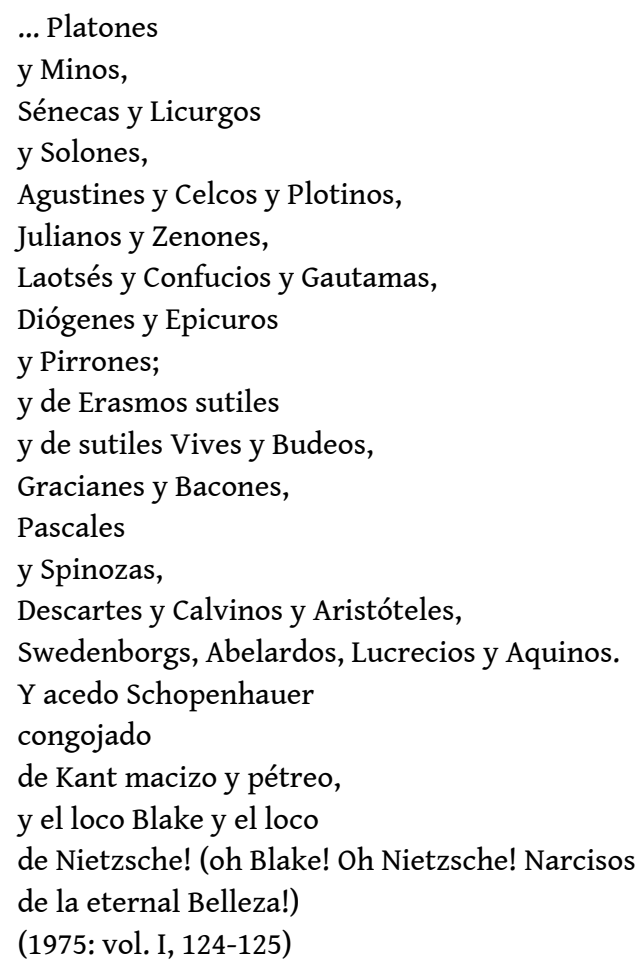

Mediante esta exhaustiva e intencionalmente desorganizada enumeración de filósofos, de Greiff pone a sus lectores frente a una panorámica que los conduce a través de su propio y caprichoso recorrido intelectual. Esta lista de nombres que sigue la trashumancia de los pingüinos a través de tiempos, territorios y sistemas de pensamiento diverso, no se propone como un corpus de estudio organizado y enciclopédico siguiendo el paradigma ilustrado. Por el contrario, aparece como un reflejo de los movimientos nomádicos de la practica lectora e intelectual del escritor colombiano y revela lo que Miguel Gómez comprende como un "afán de hibridación» que se nutre de «abundantes materiales preexistentes y coetáneos» (2002: 424).

En su ensayo «Pensée nomade» Deleuze elabora una lectura profunda y provocadora de la obra de Friedrich Nietzsche y al discutir su escritura y calificarla como una actividad de entrecruzamiento de fuerzas que se mueve por impulsos pulsionales, anota que la obra del alemán huye de los sistemas codificados de la filosofía. En su lugar, articula una red de conexiones entre «intensidades». Para ejemplificar esto, recurre al comentario del uso de nombres propios que Nietzsche hace a lo largo de su obra y que sorprende por su abundancia y extrañeza: 
C'est le plus mystérieux chez Nietzsche. L'intensité a à voir avec les noms propres, et ceux-ci ne sont ni représentations de choses (ou de personnes), ni représentations de mots. Collectifs ou individuels, les présocratiques, les Romains, les Juifs, le Christ, l'Antéchrist, Jules César, Borgia, Zarathoustra, tous ces noms propres qui passent et reviennent dans les textes de Nietzsche, ce ne sont ni des signifiants ni des signifiés, mais des désignations d'intensité, sur un corps qui peut être le corps de la Terre, le corps du livre, mais aussi le corps souffrant de Nietzsche : tous les noms de l'histoire, c'est moi... Il y a une espèce de nomadisme, de déplacement perpétuel des intensités désignées par des noms propres, et qui pénètrent les unes dans les autres en même temps qu'elles sont vécues sur un corps plein. L'intensité ne peut être vécue qu'en rapport avec son inscription mobile sur un corps, et avec l'extériorité mouvante d'un nom propre, et c'est par là que le nom propre est toujours un masque, masque d'un opérateur. (2002: 358-359)

La agudeza de esta interpretación resulta sumamente iluminadora e ilustrativa. Deleuze reconoce que el ejercicio de enumerar configura una constelación de referencias que no necesariamente deben ser interpretadas en su unidad significativa, sino como una práctica de rastreo de espacios abarcables. Este mismo ejercicio es reconocible en la obra greiffina, y con especial énfasis en un poema como la «Farsa de los pingüinos peripatéticos», donde la sobreabundancia de nombres y la enumeración de referencias tiene como propósito el reconocimiento de una red de «intensidades» cuyas constelaciones y redes de secuencia se ordenan por afinidades estéticas, musicales, afectivas, de pensamiento o asociaciones alternativas. Esta es, justamente, la lectura que se propone del pasaje enumerativo de la «Farsa de los pingüinos peripatéticos» anteriormente citado. La «Ronda final» ilustra con claridad la conexión entre la estética del catálogo greiffiana y las líneas de un pensamiento nómada de resonancia nietzscheana. Tal como el filósofo alemán, el poeta colombiano opone al orden de un conocimiento enciclopédico, una práctica de asimilación vital de intensidades que toma como puntos de enlace para construir una cartografía intelectual propia y fabricarse una genealogía poética alternativa. Y, puesto que su nomadismo es intelectual e inmóvil, el terreno de estas operaciones será inevitablemente el de la biblioteca; su práctica será la de su creativa desorganización y reorganización de su archivo cultural.

\section{Reorganizaciones del archivo y geopolíticas culturales}

Es necesario observar que mediante la reorganización del archivo literario, la poesía greiffiana efectúa una negociación de los lazos de pertenencia y las vías de diálogo con la esfera abstracta de la tradición universal. Mediante esta estrategia, de Greiff da continuidad a una práctica que, de acuerdo con Aníbal González, ya había sido iniciada a finales del siglo XIX y principios del xx por los modernistas latinoamericanos. Retomando la metáfora que González utiliza para comprender las dinámicas intelectuales de estos últimos, es posible considerar la empresa literaria del colombiano como una necesaria y subjetiva reestructuración del espacio simbólico de la biblioteca:

[The] modernista writing presupposes the existence of a Library...[which]... stands for an ideal plane, a kind of intertextual no-man's-land, where philological and literary texts jostle each other and where their placement within an arbitrary scheme (in alphabetical order, for instance) neutralizes their delicate interplay of similarities and differences. The library not only allows access to a fund of knowledge, but also allows that borrowed to be borrowed and used in an eclectic 
manner. Modernismo was, to a large extent, the appropriation and partial reorganization of the Library of European culture by Spanish America (2010: 10). abstracto de las obras y conocimientos disponibles no solo en Europa sino en un plano global, la reorganización subjetiva de este archivo se muestra como un gesto irreverente de apropiación y reconfiguración de conocimientos. Bajo esta óptica, el gesto aparentemente lúdico e inocente de la desorganización de geografías, líneas cronológicas, datos y referencias, adquiere un significado subversivo. Su reconfiguración de la historia literaria, sus deambulaciones y confusiones de rutas, los trayectos de conexiones inesperadas y azarosas ponen en marcha un ejercicio con el cual se pretende trazar una cartografía mundial de propia factura en la cual las jerarquías de centro y periferia, de moderno y antiguo, de civilización y colonias buscan desdibujarse. Al querer hacer de la tradición literaria un espacio liso, León de Greiff busca situarse en un mismo plano de localización con sus predecesores y coetáneos de América, Europa, Oriente Medio, Asia Menor, y Rusia, logrando así inscribirse como parte integrante de una cartografía literaria trans-nacional, trans-geográfica y transhistórica.

Teniendo en cuenta las observaciones anteriores, la propuesta que aquí se adelanta es la de leer los textos greiffianos a la manera de ejercicios cartograficos. Es decir, se propone considerar los poemas del colombiano como trazados de mapas poéticos en los que se consignan las diferentes líneas de sus recorridos geográfico-literarios. Bajo esta óptica, las referencias culturales incluidas en cada texto pueden servir como guía al lector para reconocer el mapa de las redes de contacto que abarca. De la misma manera, el reconocimiento de estas redes geográfico-literarias puede leerse como una práctica performativa de reconocimiento y negociación de dinámicas de sus vínculos de pertenencia local y global. Es así, pues, que mediante cada uno de sus textos, de Greiff busca insertar su obra en el espectro de la literatura mundial que, como precisa Mariano Siskind, era observado por los poetas modernistas de aspiraciones cosmopolitas como «a constellation of discourses that invoke a world of literatures, imprecisely defined by a vague and abstract notion of universality, so welcoming to marginal cultures that Latin American writers see it as a blank screen for the projection of their modern hopes» (2014: 104).

"pantalla en blanco» que menciona Siskind puede ser comprendida, hasta cierto punto, como un espacio en el que se abre la posibilidad de configurar nuevas redes de conocimiento y conexiones literarias que se superponen a los trazados que relegan a Latinoamérica a una posición de marginalidad en el plano geo-cultural de su momento histórico. Pero la proyección de cartografías alternativas que observamos en León de Greiff no constituye únicamente una negociación de los trazados de mapas globales y una rearticulación de su localización en este plano. Su pretensión de universalidad se ramifica también hacia un plano histórico. Además del estatuto de igualdad y modernidad que reclama frente al resto de tradiciones literarias y culturales contemporáneas con las que dialoga, León de Greiff quiere conquistar un estatuto de paridad con el espectro total de la historia.

untento similar al de T.S. Eliot, que propone situarse en situación de paridad tanto con el canon antiguo como con el moderno, el poeta colombiano penetra en la historia y la tradición literaria mundial como si se tratara de un plano horizontal de existencia simultánea. En su conocido ensayo «Tradition and the Individual Talent», 
T. S. Eliot se propone una definición renovadora de la idea de tradición. En lugar de comprenderla como un fenómeno secuencial, transmisible y supeditado a la linealidad histórica la entiende como un «orden de existencia simultáneo» en el que «the whole of the literature of Europe from Homer and within it the whole of the literature of his own country has a simultaneous existence and composes a simultaneous order» (1975: 38). Tanto T. S. Eliot como León de Greiff buscan configurar un espacio literario en el que Shakespeare y Baudelaire, Edgar Allan Poe y François Villon, Rubén Darío y Miguel de Cervantes coexisten y se hallan al mismo alcance ${ }^{12}$. El eje de ordenamiento cronológico se reemplaza por un principio de horizontalidad en el que se hace posible establecer sistemas de relación sobre la base de afinidades estéticas, temáticas, formales, filosóficas y de otros órdenes. En la teorización y la práctica poética del escritor norteamericano, así como en el ejercicio de escritura del poeta colombiano, el eje vertical de la historia se comprime en una dimensión espacial en la que pueden trazarse numerosas redes de conexión. Comprender la poética greiffiana como un ejercicio de espacialización de la historia se ajusta, pues, a la propuesta de leer sus poemas como ejercicios de cartografía literaria que no solamente abarcan un espectro de geografías dispersas sino también un amplio arco temporal que se extiende desde la antigüedad a la época contemporánea.

Si la «Farsa de los pingüinos» permite destacar el trazado de un mapa global de trayectos literarios, el «Relato de los oficios y mesteres de Beremundo el Lelo» ofrece un ejemplo de la codificación espacial de la historia en la poesía greiffiana. En este texto no solamente se verifica una elaboración cartográfica de gran amplitud y de signo literario, sino también un ejercicio de superposición y conjugación de temporalidades divergentes. El poema se incluye en un séptimo mamotreto, Velero Paradójico, y consiste en una narración biográfica de otro de los heterónimos: Beremundo el Lelo. A lo largo de dieciocho páginas, este último nos ofrece una narración exhaustiva de sus innúmeros viajes y múltiples ocupaciones. En el recuento de sus aventuras hace un largo inventario de territorios vistos y habitados, culturas apropiadas, profesiones ejercidas, amistadas ganadas y perdidas. Su afanosa numeración tiene como propósito hacer visible un deseo de mundo omniabarcante y evidencia la pletórica abundancia de la cultura universal que quiere hacer suya. Este poema-catálogo que actúa como una bitácora de desplazamientos, se abre con una declaración de principios que bien podríamos considerar propios de un nómada:

Yo, Beremundo el Lelo, surqué todas las rutas

Y probé todos los mesteres.

Singlando a la deriva, no en orden cronológico ni lógico -en sin orden-

narraré mis periplos, diré de los empleos con que nutrí mis ocios,

distraje mi hacer nada y enriquecí mi hastío...;

-hay de ellos otros que me callo-

(1975: vol. II, 201)

31 Los dos ejes temáticos y simbólicos son el viaje y el trabajo. El primero de estos da cuenta de la voluntad expansiva. El segundo, se presenta como posibilidad de habitar y transformar momentáneamente los lugares en los que se inserta. Beremundo aparece como un viajero que se instala en los sitios de su recorrido, los habita temporalmente y los transforma. En los versos iniciales hace manifiesta esta actitud participativa:

Catedrático fui de teosofía y eutrapelia, gimnopedia y teogonía y pansofística en

Plafagonia;

berequero en el Porce y el Tugüi, huaquero en el Quindío,

amansador mansueto - no en desuetud aún- de muletos cerriles y de onagros, no 
sé dónde;

palaciego proto-Maestre de Ceremonias de Willfredo el Velloso

...

Fui, de Sin-bad, marinero; pastor de cabras en Sicilia

si de cabriolas en Silecia, de cerdas en Cerdeña y -claro- de corzas en Córcega;

halconero mayor, primer alcotanero de Enguerrando Segundo -el de la Tour-

Miracle-;

...

Fui preceptor de Diógenes, llamado malamente el cínico:

huésped de su tonel, además, y portador de su linterna;

condiscípulo y émulo de Baco Dionisos Enófilo, llamado buenamente el Báquico

-Y el Dionosíaco, lo juro-

Fui discípulo de Gautama, no tan aprovechado, resulté mal budista, si asaz

contemplativo.

(1975: vol. II, 201-22)

Aunque la enumeración de oficios y lugares parece, de entrada, incongruente e incluso chocante por su rareza, es importante notar la voluntad de inserción activa en cada uno de estos destinos. En Plafagonia - región situada en la costa norte de Anatolia y que ya aparece mencionada como uno de los pueblos aliados de los troyanos en la Ilíada- se propone como catedrático de materias poco corrientes, rimbombantes e incluso inventadas (i.e. pansofística). Luego, sin un espacio de tránsito, salta directamente a la geografía de Colombia en el siglo veinte y se presenta primero como minero artesanal en los ríos de Antioquia - «berequero en el Porce»- y como buscador de tesoros en el departamento del Quindío. Para continuar con el efecto de desestabilización, se traslada luego a otra época y a otro continente: lo vemos como ayudante palaciego del famoso conde que garantizó la independencia del condado de Barcelona respecto de la monarquía carolingia en el año 985. Más adelante lo vemos haciendo parte de las narraciones de las Mil y una noches y de vuelta a los espacios de la mitología clásica griega. Los desplazamientos abigarrados de este poema se efectúan en una dimensión donde la historia se ha comprimido en un espacio plano y se presenta como un circuito de recorridos abarcables. Mediante este artificio literario, su nomadismo geográfico se equipara con un nomadismo histórico de similares alcances y proporciones.

En su libro The Avant-Garde and Geopolitics in Latin America, Fernando Rosenberg observa que el recurso a la espacialización de la historia en el ámbito literario es una característica prominente en la literatura modernista y vanguardista del continente. Su interpretación comprende la reducción de las categorías de ordenamiento temporal a una dimensión espacial como una estrategia de cuestionamiento de las lógicas de causalidad, temporalidad y subordinación de origen colonial que relegan el espacio latinoamericano a una posición de retraso y marginalidad. El crítico afirma que todo imaginario universalista se efectúa necesariamente desde una posición concreta, no desde un estado de universalidad abstracta y por tanto debe tenerse en cuenta el rol fundamental que tiene el "posicionamiento global» en dicho proceso de construcción de redes (2006: 36-38). El énfasis de Rosenberg al señalar el carácter localizado y periférico de la elaboración de estos mapas globales es fundamental para comprender la obra greiffiana y sus recorridos nomádicos como una producción literaria que también se halla limitada por los condicionamientos del lugar de su producción. De Greiff es plenamente consciente de las limitaciones y las condiciones de posibilidad implícitas en su propia practica poética. Para hacer evidente este elemento, es posible remitirse al texto con el que se abre su tercer mamotreto, Prosas de Gaspar, en el que se narra el nacimiento de Matías Aldecoa, uno de sus heterónimos principales: 
No en Mossul ni en Bassora, ni en Samarakanda. No en Karlskrona, ni en Abylund, ni en Stockholm, ni en Koevenhavn. No en Kazán ni en Cawpore, ni en Aleppo. Ni en Venezia lacustre, ni en la 'quimérica' Istambul, ni en la Isla-de-Francia, ni en Tours, ni en Strafford-on-Avon, ni en Weimar, ni en Yasanaia-Poliana, ni en los baños de Argel... Ni en ninguna Cibdad de ensoñación, ni en ninguna moderna factoría, ni en ningún placer minero, ni siquiera en el Polo glabro ni aledaños: pero sí en un adormilado villorrio de los Andes, vio la luz (del sol o de la luna y las constelaciones, o del familiar velón) el amigo Aldecoa (Matías, Francisco, Odín), y en los años postreros del último (por ahora) siglo.

(1975: vol. I, 69)

El mapa literario que propone de Greiff textualiza el recorrido de su imaginario poético y sugiere con mayor claridad una de las preguntas que late como constante a lo largo de toda su obra: ¿cómo se inserta este «villorio de los Andes» -espacio metonímico del continente latinoamericano- en el circuito de la cultura global? La enumeración de ciudades en las que no pudo nacer Matías Aldecoa tiene, pues, una doble finalidad. Por una parte, enfatiza en la condición arbitraria, accidental, del lugar de nacimiento de un individuo y subraya la condición de pertenencia involuntaria a una determinada localidad. En segunda instancia, el trazado que comprende localidades de Europa del norte y Europa central, Rusia, Medio Oriente e India, sitúa estos espacios en un nivel de paridad y coexistencia que los presenta como equiparables y textualmente equidistantes. La inclusión de esta localidad colombiana andina en un mapa cosmopolita, le permite a de Greiff insertarla dentro de un círculo que reúne a otras ciudades de mayor renombre, peso simbólico y carga histórica. De esta forma abre una vía de inclusión, integración y participación del territorio americano en un mapa de dimensiones globales.

Si la narración del nacimiento de Matías Aldecoa viene precedida por una larga y detallada enumeración de ciudades de distinta localización, debe prestarse atención a la pregunta por las interacciones entre lo global y lo local que allí se plantea. Al mencionarse solamente al final de una profusa enumeración de sitios de renombre histórico y peso simbólico en la historia mundial, el pequeño «villorio» destaca por su condición de marginalidad en este mapa. Se reconoce, pues, su distancia respecto de los centros culturales y los lugares de mayor reconocimiento histórico. Sin embargo, esta ciudad no se halla totalmente fuera de su circuito. Por el contrario, de Greiff busca incluirla en el trazado de este imaginario global que no solamente incluye los sitios de mayor renombre sino también el lugar desde el que se elabora este mapa de dimensiones globales. El número de ciudades que preceden su aparición en el poema constituyen, de esta forma, un horizonte en el que esta última viene a enmarcarse. Así, su práctica literaria ejerce un movimiento correctivo que reúne el espacio americano no solo sus nacientes metrópolis, sino también la dispersión de sitios aislados de las urbes- con la esfera cosmopolita y los mapas culturales más amplios.

La mención a estos espacios localizados en la geografía americana y desde los que se configura una soñada o poetizada imagen del mundo no son infrecuentes en la obra de León de Greiff. Por el contrario, se convierten en un leitmotiv de su obra. Sus personajes y los viajes de estos se construyen a partir de una consciencia de la periferia, se articulan en un movimiento de llegada desde fuera para penetrar en la esfera del mundo. Los movimientos de entrada y salida -que ejemplificaba con el comentario del «Relato de Beremundo»- tienen la función de movilizar y difuminar las líneas fronterizas que marcan la posición de marginalidad desde la que se escribe. Observado desde esta perspectiva, el movimiento de los personajes greiffianos gana una dimensión 
de rearticulación geopolítica bastante significativa. Al oscilar constantemente entre centros y periferias - tanto históricos como culturales-, al trasladarse de manera abrupta entre sitios que no guardan relaciones de estrecha cercanía y al desplazarse sin transiciones de un momento histórico a otro, desestabilizan las lógicas de ordenamiento histórico y territorial sobre las que se estructuran los cánones que relegan las obras latinoamericanas $-\mathrm{y}$ por ende la suya propia- a una posición de marginalidad. Sus construcciones poéticas ejercen una rearticulación de una imago mundi y el trazado de nuevas cartografías que permitan trazar nuevos circuitos de integración con el espacio global. Así, en la medida en la que se propone un recorrido de un mundo efectuado desde un espacio localizado y en clave latinoamericana, su nomadismo puede comprenderse como reivindicativo.

\section{Conclusiones}

El epígrafe que encabeza este artículo abre una pregunta a la que este artículo quiere brindar una respuesta parcial mediante el estudio de la obra greiffiana. La propuesta de interpretar la poesía del colombiano como una manifestación de nomadismo inmóvil busca alinear el espíritu de su obra con el impulso de rebeldía y renovación nietzcheano por el que interroga Deleuze. Así, pues, la consideración de su figura como la de un viajero inmóvil, un desordenado cosmopolita de biblioteca, logra situarse en un terreno interpretativo de mayor amplitud. En las primeras páginas del artículo se subrayó la ausencia de viajes en la biografía de León de Greiff. El objetivo de este énfasis no era, como se ha visto, el de destacar un dato anecdótico como punto de partida para el análisis. Por el contrario, este dato se adopta como un elemento interpretativo central dentro de su obra y el significado de esta dentro de sus diálogos con el panorama amplio de la literatura mundial. El elemento de quietud e inmovilidad greiffiano debe comprenderse, como se ha señalado en las páginas anteriores, como un ejercicio de reivindicación de su espacio de marginalidad. De Greiff asume su condición de desventaja como herramienta útil para reintegrarse a un espacio intelectual cosmopolita. Su sedentarismo aparece, entonces, como la condición de posibilidad esencial que le permite articular sus cartografías descentradas, librescas, anárquicas y omniabarcantes. En el laberinto desordenado de sus estanterías y en la errancia de sus lecturas, León de Greiff encuentra las posibilidades materiales para reimaginar una tradición literaria universal como un espacio de existencia simultánea y recodificar la cartografía mundial como un espacio de circulación y tránsito en el que el espacio propio, el espacio suyo latinoamericano, se halla en relación de paridad y equidistancia con respecto a otras tradiciones. De igual manera, al construir los espacios de su imaginario siguiendo una lógica de desdibujamiento de cartografías establecidas y elaborando caprichosas reinterpretaciones de mapas culturales, el suyo llega a constituirse como un arte desterritorializado que pone en cuestión y reorganiza estratégicamente las redes de afiliación a nivel local y global. Así comprendido, su nomadismo no constituye solamente una arriesgada propuesta de cosmopolitismo intelectual, sino también una valiente exploración de genealogías de relación intelectual y de exploración alternativa y heterodoxa de redes identitarias y de conocimiento. 


\section{BIBLIOGRAFÍA}

ABEYTA Michael (2012), «Maqroll and Sinbad: Death and the Time of the Nomad in Alvaro Mutis's Maqroll Novels», Revista de Estudios Colombianos, 39, Bogotá: Colombia, 14-22.

ACHING Gerard (2010), The Politics of Spanish American modernismo: By Exquisite Design, Cambridge University Press: Cambridge.

BECKMAN Ericka (2013), Capital Fictions: The Literature of Latin America's Export Age, Minneapolis: University of Minnesota Press.

CUARTAS Juan Manuel (1996), «León de Greiff: problemática del “Yo” en poesía», Thesaurus, 51(1), 111-133.

Deleuze Gilles (2002), L'île déserte. Textes et entretiens 1953-1972, D. Lapoujade (ed.), Paris: Éditions de Minuit.

Deleuze Gilles \& Guattari Félix (2002), Mil mesetas. Capitalismo y esquizofrenia, J. Vásquez Pérez (trad.), Madrid: Editorial Pretextos.

ELIOT Thomas Stern (1975), Selected Prose of T. S. Eliot, London: Faber and Faber.

GómEZ Miguel (2002), «El tiempo literario de León de Greiff», Hispanic Review, 70(3), 421-438.

GonZALlez Aníbal (2010), A Companion to Spanish American Modernismo, London: Tamesis.

GREIFF León de (1975), Obras Completas (II volúmenes), Bogotá: Editorial Tercer Mundo.

GREIFF Hjalmar de (2004), «Introducción», Obra Poética. León de Greiff (vol. I), Universidad Nacional de Colombia, III-XXIII.

MiRANDA Álvaro (2004), Leon De Greiff: En El Pais De Bolombolo, Bogotá: Panamericana.

Olmos Ana Cecilia (2016), «Lecturas errantes y cartografías críticas», R. Dhondt \& D. Vandebosch (eds), Transnacionalidad e hibridez en el ensayo hispánico: Un género sin orillas, Leiden: Brill, 36-48.

RAMIREZ RojAS Marco (2016a), «León de Greiff. Intertextos medievales de su poesía», Revista de Estudios de Literatura Colombiana (38), Universidad de Antioquia, Medellin: Colombia, 13-37.

RAMIREZ Rojas Marco (2016b), «Marginalidad del artista y reivindicación cosmopolita. León de Greiff lee a François Villon», Revista Canadiense de Estudios Hispánicos, 4(3), 606-626.

ROSENBERG Fernando (2006), The Avant Garde and Geopolitics in Latin America, Pittsburg: Pittsburg University Press.

SALAMANCA Óscar (2015), «Descentramiento del sujeto y de la escritura en la poesía de León de Greiff», Estudios de Literatura Colombiana (36), Bogotá: Colombia, 59-79.

SISKIND Mariano (2014), Cosmopolitan Desires: Global Modernity and World Literature in Latin America, Evanston: Northwestern University Press.

VÁSQUEZ Julián (2006), El gran viaje atávico. Suecia y León de Greiff, Medellín: Editorial Tambor de Arlequín. 


\section{NOTAS}

1. Vale la pena mencionar la influencia que la obra greiffiana tuvo en la construcción del imaginario y la poética de la errancia y el viaje de un autor tan ampliamente conocido como Álvaro Mutis. Este último no solamente retoma de León de Greiff el nombre y las características de uno de sus personajes heterónimos, Matías Aldecoa, sino que también juega con la temática de un nomadismo de corte intelectual. Michael Abeyta analiza estas cuestiones en la novelística de Mutis en su artículo «Maqroll and Sinbad: Death and the Time of the Nomad in Alvaro Mutis's Maqroll Novels».

2. En 1925 publica Tergiversaciones, su primer poemario. En 1930 aparece Libro de Signos, en 1936 Variaciones alredor de nada, en 1937 Prosas de Gaspar, en 1954 Fárrago, en 1957 Bajo el signo de Leo y Velero Paradójico. Su último poemario, Nova et Vetera, aparece en 1973.

3. En Capital Fictions: The Literature of Latin America's Export Age, Erika Beckman propone un término crítico para acercarse a la estética enumerativa y acumulativa propia de los escritores modernistas latinoamericanos. El concepto que acuña es el de «the modernist import catalogue» (2013: 43). El capítulo 2 de su libro está dedicado a analizar las confluencias entre el discurso mercantil y de acumulación de bienes de lujo y capitales con su correspondiente replicación estética en las prácticas poéticas de los escritores de la época. A diferencia de sus predecesores, la acumulación que transparentan los textos greiffianos no es la de objetos de lujo o mercancías importadas, sino la de capitales culturales que también llegan desde el espacio europeo. Su práctica enumerativa, no obstante, entronca con la de Silva, Darío y otros modernistas de finales del XIX y principios del XX.

4. Esta información se halla confirmada tanto en la cronología elaborada por Hjalmar de Greiff para la introducción a la Poesía Completa publicada por la Universidad Nacional (2004), como en la biografía elaborada por Álvaro Miranda (2004).

5. León de Greiff sale por primera vez del país en 1945, como enviado consular con destino a México. Para este entonces, ya ha compuesto los primeros seis «mamotretos» de su obra. Luego, a finales de la década de 1950, realiza un viaje de mayor duración que lo lleva a Europa, Rusia, China y le permite asentarse por un par de años en Estocolmo como agregado cultural. En los libros publicados antes de esta fecha, no obstante, el poeta ya había configurado el imaginario cosmopolita que define su obra. Este viaje tardío, valga decirlo, no tiene un impacto verdaderamente transformador en la manera como De Greiff articula su visión y su proyección del mundo. Los textos que produce luego de su estancia europea van a mantenerse dentro de las mismas líneas estéticas y temáticas consolidadas en sus poemarios anteriores. Debe anotarse, no obstante, que resulta muy interesante acercarse a los textos que de Greiff escribe durante su viaje y que consigna a la manera de una bitácora de su estancia en los países nórdicos. Estos se hallan recopilados bajo el título de "Correo de Estocolmo» y han sido analizados por Julián Vásquez en El Gran Viaje Atávico: Suecia y León de Greiff (2006).

6. En Cosmopolitan Desires: Global Modernity and World Literature in Latin America Mariano Siskind define este término como una articulación discursiva de la necesidad latinoamericana de apuntar hacia una modernización que se codifica en términos cosmopolitas (2014: 104). En la introducción a su libro, Siskind lo define también como «opening to the world [that] permitted an escape from nationalist cultural formations and established a symbolic horizon for the realization of the translocal aesthetic potential of literature and cosmopolitan forms of subjectivation» (2014: 3).

7. El recurso a las ideas de Gilles Deleuze y Félix Guatari para el análisis de las obras de León de Greiff ha sido ya desarrollado en los estudios de Oscar Salamanca (2015) y Juan Manuel Cuartas (1996). No obstante, el foco de estudio de estos últimos no es la noción de nomadismo, sino la desestabilización de la noción de «yo» y la desarticulación de los procesos de articulación subjetivos en la poesía del colombiano. 
8. En el artículo «Marginalidad del artista y reivindicación cosmopolita. León de Greiff lee a François Villon» (Ramírez, 2016b) se discute en detalle la identificación transhistórica entre el escritor colombiano y el poeta medieval francés.

9. Para una discusión de la asimilación de elementos medievales y la identificación con la figura del juglar en la poesía greiffiana, ver el artículo «León de Greiff. Intertextos medievales de su poesía» (Ramírez, 2016a).

10. Gerard Aching defiende la tesis de que la estética del modernismo no debe entenderse únicamente como una táctica de evasionismo. Por el contrario, guiándose por la lógica de una estética negativa de Adorno, comprende que estas manifestaciones de alejamiento también pueden interpretarse como una forma de compromiso. En The Politics of Spanish American 'Modernismo' afirma esta idea:

«Embedded in the polemics over what may be termed the movement's escapist or evasive detachment is an imposes anachronism (...) It is my intention to resemanticize this critical commonplace and speak of detachment as an assertive engagement, that is to say, as the will to embellish from a precise cultural and discursive location - «arriba y afuera» (above and outside), as Julio Ramos succinctly states» (3)

11. El artículo «Lecturas errantes y cartografías críticas», Ana Cecilia Olmos hace un análisis de la errancia y el nomadismo en las obras narrativas de Sergio Chejfec y Juan Villoro. A pesar de la diferencia en los géneros y de la especificidad narrativa y ensayística del corpus que analiza, los planteamientos de Olmos me parecen útiles para estudiar el nomadismo intelectual greiffiano, entendido como un ejercicio de desterritorialización.

12. El texto de Eliot fue publicado en 1919, seis años antes de que saliera a la luz el primer poemario de León de Greiff. Es muy poco probable que uno hubiese leído al otro, o que de Greiff hubiese podido derivar su visión de la tradición de los planteamientos del poeta y crítico norteamericano. Sin embargo, la coincidencia en sus visiones es llamativa.

\section{RESÚMENES}

Este artículo estudia la obra poética de León de Greiff (1895-1976) como una manifestación de nomadismo intelectual. Me acerco a su poesía como a la de un viajero inmóvil que, a través de una reorganización del archivo literario occidental, se fabrica una imagen comprensiva del mundo por medio de una asimilación subjetiva y caprichosa de lecturas. Su nomadismo intelectual abre la puerta a una discusión sobre la negociación de sus afiliaciones locales y cosmopolitas. Para analizar su obra, propongo un acercamiento detallado a ciertos poemas en los que observo una construcción textual de mapas intelectuales globales que dan cuenta de sus desplazamientos. Las herramientas conceptuales de este artículo se fundamentan en las propuestas sobre nomadología de Gilles Deleuze y Féliz Guattari, en los conceptos de «deseo de mundo» y cosmopolitismo de Mariano Siskind y en la idea de «espacialización de la historia» de Fernando Rossenberg.

This article studies the poetic works of León de Greiff (1895-1976) as a manifestation of intellectual nomadism. I approach his poetry as the literary creation of a still-traveler who undertakes the task reorganizing the Western literary archive. I contend that his subjective appropriation of a wide range of cosmopolitan literary sources provides him with a 
comprehensive view of the world where he can insert himself at ease. This nomadic exploration of the literary world opens the door for a renegotiation of his local and global attachments. I analyze the construction of world literary maps and the haphazard trajectories of León de Greiff's explorations from the perspective of Gilles Deleuze and Féliz Guattari's conceptualization of "nomadology." Additionaly, I dialogue with Mariano Siskind's theorization of cosmopolitanism, his concept of "deseo de mundo," and Fernando Rosenberg's theorization around "geopolitics" and "specialization of history"

Cet article propose une lecture de la poésie de León de Greiff (1895-1976) en tant que manifestation de nomadisme intellectuel. L'œuvre de de Greiff apparaît comme celle d'un «voyageur immobile» qui réorganise l'archive littéraire occidental à partir d'un endroit fixe. Son appropriation subjective de nombreuses sources poétiques de signe cosmopolite permettent au poète de construire une image du monde très compréhensive et dans laquelle il peut s'inscrire à son insu. Cette exploration nomadique de la littérature ouvre la porte à une négociation de ses propres affiliations d'ordre local et global. Ce travail analyse cette construction de cartographies mondiales et les connections littéraires qui s'opèrent dans ces poèmes à partir des idées sur la «nomadologie » articulées par Gilles Deleuze et Félix Guattari, ainsi qu'à partir des idées sur le cosmopolitisme et le «deseo de mundo » de Mariano Siskind et les théories sur la «spacialisation de l'histoire » de Fernando Rosenberg.

\section{ÍNDICE}

Palabras claves: León de Greiff, nomadismo, desterritorialización, cosmopolitismo, Deseo de mundo, poesía colombiana

Keywords: León de Greiff, nomadism, deterritorialization, cosmopolitanism, Deseo de mundo, colombian poetry

Mots-clés: León de Greiff, déterritorialisation, cosmopolitisme, Deseo de mundo, poésie colombienne

\section{AUTOR}

\section{MARCO RAMÍREZ ROJAS}

Maître de conférences en Littérature Latino-Américaine

Lehman College, City University of New York

marco.ramirez@lehman.cuny.edu

marcoramirezrojas@gmail.com 